restriction endonucleases with infrequent recognition sites. $J$ Clin Microbiol 1990;28:2059-2063.

26. Miele A, Bandera $M$, Goldstein BP. Use of primers selective for vancomycin resistance genes to determine van genotype in enterococci and to study gene organization in vanA isolates. Antimicrob Agents Chemother 1995;39:1772-1778.

27. Humar A, Dedier I, Campbell I, Brunton J, Willey B, Low D, et al. Clinical and microbiological analysis of a vancomycin-resistant Enterococcus outbreak in a dialysis population. Presented at the 36th Annual Interscience Conference on Antimicrobial Agents and Chemotherapy; September 1996; New Orleans, LA. Abstract J3.

28. Berntson A, Green K, Willey B, Fleming CA, Blacklock A, Richardson $\mathrm{H}$, et al. Emergence of vancomycin-resistant enterococci in Ontario. Presented at the 37th Annual Interscience Conference on Antimicrobial Agents and Chemotherapy; September 28-October 1, 1997; Toronto, Ontario, Canada. Abstract C-154.

29. Willey BM, Blacklock A, Ontario VRE Surveillance Study, McGeer A Low DE. Molecular epidemiology of the emergence of vancomycinresistant enterococci in Ontario, Canada. Presented at the 36th Annual Interscience Conference on Antimicrobial Agents and Chemotherapy; September 15-18, 1996; New Orleans, LA. Abstract C16.

30. Boyce JM, Opal SM, Chow JW, et al. Outbreak of multidrug resistant Enterococcus faecium with transferable vanB class vancomycin resistance. J Clin Microbiol 1994;22:1148-1153.

31. Moreno F, Grota P, Crisp C, Magnon K, Melcher GP, Jorgensen JH, et al Clinical and molecular epidemiology of vancomycin-resistant Enterococcus faecium during its emergence in a city in southern Texas. Clin Infect Dis 1995;21:1234-1237.
32. Pegues DA, Pegues C, Hibberd B, Ford D, Hooper D. Emergence and dissemination of a highly-vancomycin resistant $\operatorname{van} \mathrm{A}$ strain of Enterococcus faecium at a large teaching hospital. J Clin Microbiol 1997;35:1565-1570.

33. New York State Department of Health. Supplemental Infection Control Guidelines for the Care of Patients Colonized or Infected With VancomycinResistant Enterococci in Hospitals, Long Term Care Facilities, and Home Health Care. Health Facilities Series 95-14. State of New York Department of Health memorandum. Albany, NY: NYS Dept of Health; 1995.

34. Chia JKS, Nakata MM, Parks SS, Lewis RP, McKee B. Use of bacitracin therapy for infection due to vancomycin-resistant Enterococcus faecium. Clin Infect Dis 1995;21:1520.

35. McGeer A, Cann D, Mustachi B, Willey B, Wigston C, Low DE. Evaluation of oral bacitracin therapy for the eradication of colonization of resistant enterococci. Presented at the 35th Interscience Conference on Antimicrobial Agents and Chemotherapy; September 1995; San Francisco, CA Abstract J142.

36. O'Donovan CA, Fan-Havard P, Tecson-Tumang FT, Smith SM, Eng RHK. Enteric eradication of vancomycin-resistant Enterococcus faecium with oral bacitracin. Diagn Microbiol Infect Dis 1994;18:105-109.

37. Montecalvo MA, deLancastre $H$, Carraher M, Gedris C, Chung M, Van Horn K, et al. Natural history of colonization with vancomycinresistant Enterococcus faecium. Infect Control Hosp Epidemiol 1995; 16:680-685.

38. Green M, Barbadora H, Michaels M. Recovery of vancomycin-resistant gram positive cocci from pediatric liver transplant patients. $J$ Clin Microbiol 1991;29:2503-2506.

\title{
Surgical-Wound Surveillance
}

\section{Gina Pugliese, RN, MS Martin S. Favero, PhD}

Mitchell and coinvestigators from the Centre for Infectious Diseases and Microbiology Laboratory Service, Westmead Hospital and University of Sydney, New South Wales, Australia, evaluated two methods of postdischarge surgical-wound surveillance and compared the incidence and outcomes of wound infections that develop prior to patients' discharge with those that develop after hospital discharge. A total of 1,360 inpatients who underwent major elective surgery in an 800-bed teaching hospital in western Sydney between February 1996 and July 1997 were followed prospectively.
Overall, 138 wound infections were diagnosed (incidence 10.1\%), of which $44(32 \%)$ were diagnosed before discharge (average 10.4 days postoperatively) and the remainder after discharge (average 20.6 days postoperatively). Postdischarge survey forms were returned by 782 patients $(58 \%)$ and 680 by surgeons (50\%). When forms were returned by both surgeons and patients for the same wound (641 cases), there was substantial agreement in diagnosing infection or no infection.

The authors concluded that the majority of nosocomial surgical-wound infections develop after the patient's discharge from hospital. A postdischarge surveillance program, including self-reporting of infections by patients and return of questionnaires by patients and surgeons, is feasible in an Australian hospital setting. However, such a program is labor- and resource-intensive, and strategies to increase return of questionnaires are required.

This study supports findings in US studies that postdischarge surveillance is essential as the length of stay continues to decrease. Moreover, the expansion of outpatient surgery with no overnight stay has dramatically changed the methods for surveillance. Follow-up questionnaires have been found to be a useful surveillance tool.

FROM: Mitchell DH, Swift G, Gilbert GL. Surgical wound infection surveillance: the importance of infections that develop after hospital discharge. Aust N Z J Surg 1999;69:117120. 